\title{
Natural acquisition of the second language (12) through routine movements in children
}

\author{
LAURA RIO , NICOLETTA DI RUBBO, FILIPPO GOMEZ-PALOMA \\ Department of Human, Philosophical and Educational Science, University of Salerno, Salerno, Italy
}

\begin{abstract}
Rio, L., Di Rubbo, N. \& Gomez-Paloma, F. (2014). Natural acquisition of the second language (12) through routine movements in children. J. Hum. Sport Exerc., 9(Proc1), pp.S355-S358. Research is increasingly showing that the brains of people who know two or more languages are different from those who know just one - and those differences are all for better. (Kluger, J., Times Magazine 2013). Multilingual people, studies show, are better at reasoning, at multitasking, at grasping and reconciling conflicting ideas. A bilingual brain is proving to be more flexible and more resourceful. Gregg Roberts, a language-immersion specialist with the Utah State Office of Education, says, "Monolingualism is the illiteracy of the 21st century", (Kluger, J., Times Magazine 2013). This preliminary project would demonstrate that acquiring a second language for children is possible through an alternative teaching proposal that integrates body into the natural language acquisition process thanks to a new didactic method fun and exciting which stimulates children to consider the second language more friendly and less hostile. The groups we are going to consider attend the last year of the infant school, they come from different schools, the first group, (the random group) attends regularly at school, traditional frontal lessons of the second language (L2), two hours a week; the second group, (experimental group) doesn't learn the second language at school but will start our experimental programme which allows them to acquire the second language through routine movements during the gymnastic hours for one hour a week. In this way children start to decode the language and slowly become confident with it. This method consider that teaching the second language will become more difficult as children grow, and grow their ability to the movements: as movements become more complicated so will the vocabulary become more complex (Doron, H. ready-steady-move 2007-2013). Starting from this preliminary study we would demonstrate that the experimental group, compared to the random group, even if exposed to the second language one hour a week less than the random group, will be able to remember and perform routine movements if exposed to the second language and imitating the teacher: smiling, laughing, turning around, walking, reaching, sitting, running, and so forth. This methodology will be more efficient than a traditional teaching lesson because children will learn naturally and in their natural environment. Dr. Asher calls this "a language-body conversation" because the parent/teacher speaks and the infant answers with a physical response; in this case the teacher gets immediate feedback that the children understand when they give an appropriate physical response (Kovács, 2010). To conclude, we must consider that children are happy when they can play, move and sing, all better if these activities are combined. There is a saying that a child does not do what he has learnt, but rather the contrary: he learns what he has already done (Kovács, 2010). That's why in early language acquisition, activities linked with movements, competitions, dance and group games are very important. All these need time to develop receptive skills (understanding based on listening) before the productive use of the language appears (Kovacs, 2010). For the future we would refine the method, consider a wider group of children and of different ages, and experiment the natural language acquisition also in specific motor disciplines. Key words: (L2)SECOND LANGUAGE, NATURAL ACQUISITION, ROUTINE MOVEMENTS, TOTAL PHYSICAL RESPONSE.
\end{abstract}

Corresponding author. Department of Human, Philosophical and Educational Science, Education Science, University of Salerno, Salerno, Italy.

E-mail: riolaura@alice.it

8th INSHS International Christmas Sport Scientific Conference, 5-7 December 2013. International Network of Sport and Health Science. Szombathely, Hungary.

JOURNAL OF HUMAN SPORT \& EXERCISE ISSN 1988-5202

(c) Faculty of Education. University of Alicante

doi:10.14198/jhse.2014.9.Proc1.20 


\section{INTRODUCTION}

Our brain is the most complex of all our organs: the seat of consciousness, it is also tasked with controlling every system of the body from the involuntary beating of the heart to the deliberate movements of the arms and legs (Doron, H. ready-steady-move 2007-2013). The brain can be seen as a super-sense or sensory motor. The brain is much like a computer and its functions are all well organized. The brain structure is very complex and articulated, the largest part is called cerebrum and one of its function is memory, it is divided into two hemispheres that look symmetrical but they are slightly different (www.serendip.brynmawr.edu).

The right hemisphere is the seat of emotions and intuition and it can be stimulated through music, songs and exercises that involve paying attention to timing, acting, stories, etc....

The left side is the house of logical skills such as math, language and speech, its functions can be developed by movements that use spatial memory, hand-eye coordination or exercises that involve hand gestures.

Each hemisphere of the brain is responsible for the motor control on the opposite side of the body, so all the activities which children will do through our preliminary project are going to stimulate both left- and rightside brain functions, combining a language-learning element with the physical routines.

Our preliminary project wants to develop the natural acquisition of the second language through routine movements to help children to grow better in coordination and to encourage bilateral neural connections.

\section{METHODS}

We think to work with a sample of 40 children, all children attend the last year of infant school. They belong to two different groups and school, the first group, the random group attends regularly the second language (L2) at school but through traditional frontal lessons, two hours a week. The second group, our experimental one doesn't learn the second language at school but will start the experimental program that allows them to acquire the second language through routine movements during the weekly gymnastic hour. We want to specify that the two groups will learn the same vocabulary and the grammar but into two different ways. Our experimental group will be submitted to the teacher's instructions in English language during physical education hour twice a week, while the random group will learn English always in their classroom.

During the experimental lessons teacher will make instructions in English and children will imitate him soon after, doing the action and repeating the words. In this way the group that will undergo the training start to decode the language and slowly become confident with it. Lesson after lesson children will understand well what the teacher says and they will do the physical exercises without to watch him, but repeating and making alone the movement. The language will become more and more complicated and so the physical exercises too. So at the end of the school and of our program children will have a very rich English vocabulary that they well understand and that they can appropriately use too. The process of this training will be very fun and stimulating. At the end of the training we will go to compare the two groups, on one side the random group which have studied English in a traditional way and on the other side the our experimental group. 


\section{Procedure}

We will start to say that our programme will be divided into three phases: the first one is the easiest during which the teacher will teach only some movements like: jump, hop, skip, run, walk, sit, lay, crawl, touch, breath, climb, etc...and adjectives: fast, slow, etc... during the second phase the teacher will put together the movements, the adjectives and some of the name of the tools they use, like: hula-hoop, rope, ball, bawling pin, etc... focusing on their characteristics too: the big ball, the red bawling pin, the large hula hoop, the long rope, etc... During the third and last phase the teacher will put together all the vocabulary used associating it with the preposition and some other words which he can really show to them: floor, wall, basket, door, bench, ladder, etc. and give more complicated instructions, for example: sit on the floor! Hop in the large hula-hoop! Run fast and touch the white wall! Breath slow! Climb on the gymnastic ladder! Etc...

By our preliminary studies we can formulate two programmes to which children belonging to the experimental group will be submitted:

\section{Movement Program}

- $\quad$ Engage in moderate to vigorous exercise

- $\quad$ Encourage proper body relaxation through breathing and stretching

- $\quad$ Practice coordination, flexibility, balance and strength

- $\quad$ Explore body awareness through varied movements

- Develop an awareness of personal and group space

- Improve the sense of rhythm

\section{Language Program}

- Increase children's confidence in their ability to learn and speak a second language

- Introduce basic target language vocabulary in a wide range of subjects

- $\quad$ Expose children to target language phonetics, to encourage proper accent

- Demonstrate the target language directly, rather than by translation (Doron, $\mathrm{H}$. ready-steady-move 2007-2013).

\section{DISCUSSION AND CONCLUSIONS}

We will get immediate oral feedback that is the child understood when children give back an appropriate physical response, using the Asher's strategy of the Total Physical Response. This approach has some similarity to how children seem to learn their first language. The strategy of the total physical response is to have the students listen to a command in a foreign language and immediately obey with a physical action (Asher, 1969). Students learn a foreign language by physical performing actions based first on the commands the instructors gives and then, later on, on the command of the another students too (Asher, 2003). So after one year the two groups will be compared simply making question and let them to choose the answer they prefer. We would demonstrate that our experimental group will obtain three main benefits compared to the random group: a basic fitness through a fun movement routine; a good language learning; and self-confidence. By combining these three, we will create a unique learning environment that will stimulate the mind and body together (D. H. 2007-2013). 


\section{REFERENCES}

1. Asher, J.J. (2003). Learning another language through actions.

2. Doron, H. Ready steady move (2007-2013) - www.ready-steady-move.com home.

3. Doron, H. \& Kovács, J. (2010). Learning based on activity. The music of language.

4. Kluger, J. (2013). Bilingual Boost. Times Magazine, 182(5), pp.26-29. 